\title{
Surgical strategies in childhood craniopharyngioma
}

\author{
Jörg Flitsch ${ }^{1}$, Hermann Lothar Müller ${ }^{2}$ and Till Burkhardt ${ }^{1}$ \\ 1 Interdisciplinary Endocrinology/Pituitary Surgery, University Hospital Hamburg-Eppendorf, Hamburg, Germany \\ 2 Department of Pediatrics, Klinikum Oldenburg, Oldenburg, Germany
}

Edited by:

Rolf-Dieter Kortmann, University

Clinic, Germany

\section{Reviewed by:}

Joseph George Verbalis, Georgetown

University, USA

Edward Raymond Laws, Brigham and

Women's Hospital, USA

\section{*Correspondence:}

Jörg Flitsch, Interdisciplinary

Endocrinology/Pituitary Surgery,

University Hospital

Hamburg-Eppendorf, Martinistr. 52,

20246 Hamburg, Germany.

e-mail: flitsch@uke.de

\begin{abstract}
Craniopharyngiomas are biologically benign lesions (WHO Grade 1) of the sellar and suprasellar region, associated with a serious morbidity. About $50 \%$ of these tumors become clinically apparent during childhood. Clinical symptoms include headaches, chiasm syndrome, hydrocephalus, pituitary insufficiencies, and obesity. Growth arrest is a typical symptom in children. The treatment of craniopharyngiomas includes surgery as well as radiotherapy. The goal of surgery varies according to the tumor location and extension and may range from complete resection to biopsy. Surgical complications are well known and cause constant evaluation of surgical strategies. Diencephalic obesity is related to surgical manipulation of hypothalamic tissue. Therefore, a classification system for craniopharyngiomas based on preoperative MRI is suggested by the authors. Recurrences are frequent in craniopharyngiomas, even after complete or gross-total resection. Radiotherapy is therefore recommended to patients with incomplete resections. However, the ideal time for radiotherapy after surgery is under discussion. The treatment of craniopharyngiomas requires an interdisciplinary and multimodal approach. Each patient should receive an individually tailored treatment. Surgically, different approaches as well as different degrees of resection can be considered, depending on tumor location and tumor extension.
\end{abstract}

Keywords: craniopharyngioma, surgery, childhood, pituitary insufficiency, hypothalamic obesity

\section{INTRODUCTION}

Although considered benign lesions by biological means, the (surgical) treatment of craniopharyngiomas remains a true challenge for physicians (Komotar et al., 2009; Crowley et al., 2010). The problems accompanied by craniopharyngiomas are caused by the delicate location of these tumors, supposedly arising from remnants of the Rathke's pouch and connected to neuroendocrine tissue of the pituitary, the pituitary stalk, or/and hypothalamic structures. Especially during childhood, when body development and growth are immediately influenced by the hypothalamicpituitary axis, any disruption of the neuroendocrine function has severe consequences for the patient. Impaired cognitive and social abilities are reported independent of endocrine insufficiencies (Ondruch et al., 2011). Any surgical treatment should consider the rule "primum non nocere" however, surgically induced complications/loss of functions are well known and lead to a continuous evaluation of surgical strategies.

Clinical symptoms of childhood craniopharyngiomas include growth arrest, headaches, chiasmatic syndrome, hydrocephalus, panhypopituitarism, and obesity, depending on the exact location of the tumor and its size. After CT- and MR-tomographic confirmation of a tumor in the sellar/suprasellar region and an endocrinological work-up, most patients are transferred to the neurosurgeon for surgical treatment. Preoperative imaging cannot replace the histological analysis and diagnosis "craniopharyngioma" - however certain typical characteristics make the diagnosis likely (Rennert and Doerfler, 2007). Goals of surgery can be: histological confirmation of diagnosis, relief of mass effects, treatment of hydrocephalus, preservation of hormonal function, avoidance of complications, and if possible, complete resection (CR) of the pathology. Especially in older publications, the surgical strategy generally opted for complete/gross-total tumor resection. It is indisputable, that aggressive surgical procedures more frequently lead to hypopituitarism or - even worse - hypothalamic damage and obesity (Lustig et al., 2003). Therefore, a different approach is to preserve endocrine function and avoid pituitary stalk and hypothalamic manipulation as much as possible, accepting an incomplete resection (Schubert et al., 2009). These patients are usually candidates for radiotherapy (Becker et al., 1999; Smee et al., 2011).

\section{ANATOMICAL CONSIDERATIONS AND SUGGESTION OF A MRI CLASSIFICATION}

As already mentioned, craniopharyngiomas are midline lesions of the middle cranial fossa, considered to arise from remnants of the Rathke's pouch. About $30 \%$ of the tumors have an intrasellar/infradiaphragmatic origin, whereas the rest either has its major extension above the sella turcica underneath the optic chiasm, or a mostly supra-/retrochiasmatic extension usually into the third ventricle, affecting hypothalamic structures and possibly leading to occlusive hydrocephalus. Depending on its location, the tumor causes different symptoms, e.g., hydrocephalus in intraventricular tumors, whereas growth arrest, pituitary insufficiency and Diabetes insipidus are more likely the leading symptoms in infradiaphragmatic and infrachiasmatic tumors. Tumors originating from the pituitary stalk are frequently leading to chiasmatic syndrome. All types are connected with headaches. In cases of intrasellar tumors or intra- and suprasellar tumors, the floor of 
the sella turcica is usually enlarged. Most surgeons will advice transsphenoidal surgery for patients suffering from these lesions (Abe and Ludecke, 1997).

In supradiaphragmatic-infrachiasmatic lesions, the region may be reached by a transcranial as well as a transsphenoidal approach. Whereas the access morbidity is considered less in transsphenoidal approaches, the control of neurovascular structures may be limited. Recently, several reports have been published showing good results by extended transsphenoidal surgery (see below). In all lesions arising from the pituitary stalk, the attempt of a complete/gross-total surgical resection frequently leads to partial or complete hypopituitarism.

Suprachiasmatic lesions are generally considered difficult to treat, connected with high morbidity, and frequently incompletely resected. As published by Müller (2011) and Müller et al. (2011), the attempt of surgical removal of tumor tissue beyond the mammillary bodies endangers hypothalamic structures and may cause hypothalamic obesity. Taking these considerations into account, a classification according to preoperative MRI is suggested, since this may influence the surgical strategy (Figure 1). Type 1 craniopharyngiomas are located below the diaphragma sellae, whereas Type 2 tumors are supradiaphragmatic and infrachiasmatic. Type 3 craniopharyngiomas are located above the chiasm (and usually retrochiasmatic, extending into the third ventricle). The latter Type should be subdivided into Type A and B with respect to the mammillary bodies, since Type $\mathrm{B}$ can be connected to severe hypothalamic damage, when approached by aggressive surgery (Müller et al., 2011). Different transcranial approaches to reach the area can be considered, as discussed later. Only few Type 3 craniopharyngiomas (mostly cystic) are good candidates for transsphenoidal surgery.

\section{SPECIAL CONSIDERATIONS IN CHILDHOOD}

General precautions have to be taken in children aged 10 or younger, since the "normal" intraoperative blood loss may cause life-threatening hypovolemic hypotension. Therefore, an experienced anesthesiology team is mandatory, as well as a meticulous surgical hemostasis. The use of the Mayfield pin fixation has to be carefully performed especially in children, since impression fractures with consecutive epidural hematomas are known and published complications (Yan, 2007).

As for the development of the skull base, transsphenoidal surgery is possible in infants from aged 3 years and older, since the pneumatization of the sphenoid sinus should have started (Figure 2; Flitsch et al., 2000). For maximum safety in these patients, the use of a microdoppler, fluoroscopy, or/and neuronavigation is recommended to avoid vascular complications.

\section{TRANSCRANIAL PROCEDURES}

The treatment of Type 2 and Type 3 craniopharyngiomas can be performed via transcranial approaches. Craniopharyngiomas arising from the pituitary stalk and those lesions extending into the infundibulum can be reached by a classical pterional or subfrontal route (Liu et al., 2010). Limitations are that the optic nerves/optic chiasm usually lay in front of the tumor and therefore the surgical window is limited (Figure 3). Also, the identification of the pituitary stalk can be difficult and therefore is at high

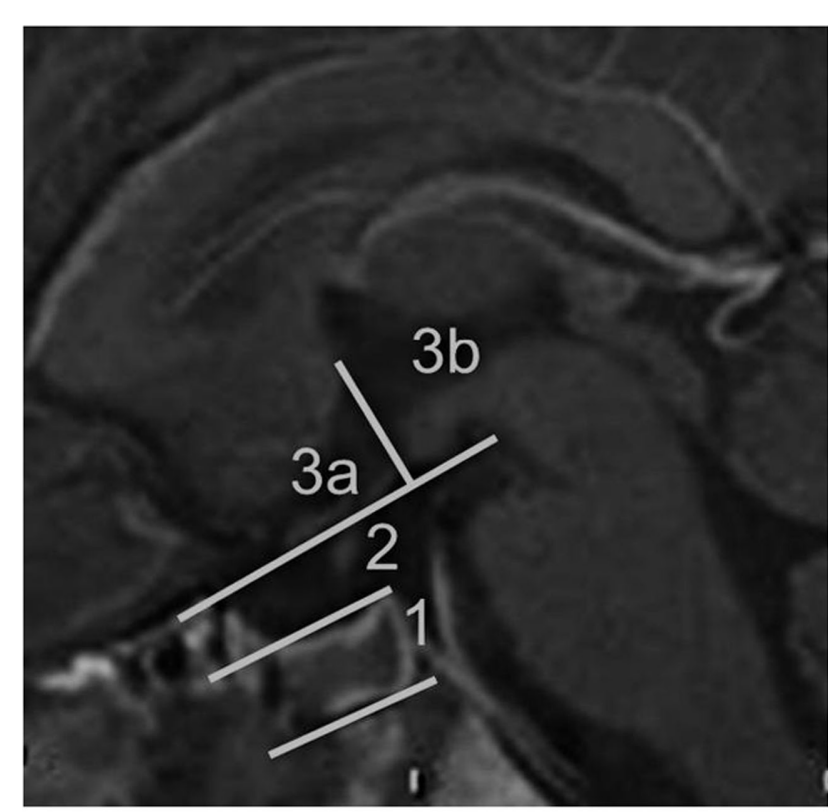

FIGURE 1 | Sagittal MRI of the midline. Suggestion of a classification system of craniopharyngiomas by preoperative MRI criteria. The intra- and suprasellar region can be divided into three sections. Section 1 is limited by the diaphragm sella, section 2 is below the optic chiasm and the mammillary bodies, section 3 is above the chiasm and mammillary bodies, subdivided into an area anterior and posterior of the mammillary bodies. In this particular patient, a transsphenoidal surgery of a Type 1

craniopharyngioma was performed previously, as can be seen by fluid within the sphenoid sinus. Section 1 is usually reached by the transsphenoidal route, whereas section $3 a$ and $3 b$ is mostly reserved for transcranial procedures. Depending on the tumor extension, section 2 can be reached by transcranial as well as transsphenoidal procedures.

risk. Tumors extending into the third ventricle can be reached by opening of the lamina terminalis behind the optic chiasm (Maira et al., 2000). Tumor cysts can be opened, however, for removal of the cyst wall or solid parts, the adjacent hypothalamic tissue is more or less manipulated. Another approach for large tumors within the ventricle is the transventricular route through a lateral ventricle and the foramen of Monroi (Konovalov, 1993). This approach may be considered in obstructive hydrocephalus. Retrosigmoid approaches for uncommon posterior fossa tumor extensions are rarely necessary. In all cases of incomplete tumor removal during transcranial procedures, catheters connected with, e.g., a Rickham reservoir can be inserted into remaining cysts for later aspiration or instillation of sclerosing substances.

\section{TRANSSPHENOIDAL PROCEDURES}

Microscopic transsphenoidal surgery remains the standard approach to the pituitary region (Fahlbusch and Hofmann, 2008). Endoscopically assisted techniques have been developed over the last two decades and enrich the surgical options (FernandezMiranda et al., 2011). Except for very small children with lack of at least partial sphenoid sinus pneumatization (up to age 3), this approach is suitable for patients with infradiaphragmatic lesions as 


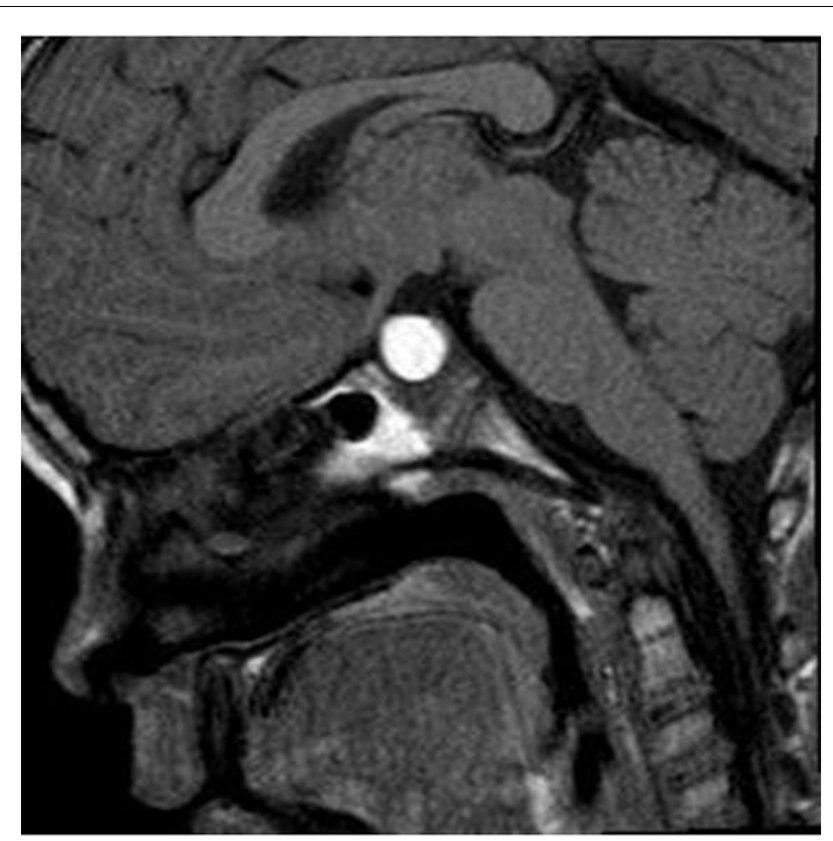

FIGURE 2 | Sagittal MRI of a child with an intra- and suprasellar craniopharyngioma reaching the optic nerves (Type 1). Special attention has to be given to the partial pneumatization of the sphenoid sinus, since the thick bone has to be drilled during the access to the sella. This can cause problems in orientation for the surgeon and endanger the carotid arteries, which may be solved by the use of a microdoppler and/or neuronavigation.

well as supradiaphragmatic (cystic) Type 2 craniopharyngiomas. Reports of transsphenoidal resections of tumors within the third ventricle exist (Gardner et al., 2008; Kitano and Taneda, 2009; Coppens and Couldwell, 2010). Especially in childhood, the incomplete pneumatization of the sphenoid sinus may require extensive drilling to access the target (Figure 2). As mentioned, technical help of fluoroscopy, microdoppler, and neuronavigation are mandatory (Figure 4). It is of importance to mention, that in Type 1 lesions the pituitary is anterior of the tumor and has to be incised and moved laterally to access the tumor. For Type 2 lesions without extension into the sella, a supradiaphragmatic access is chosen, leading to an intraoperative CSF leak in all cases, which may be difficult to close. With the use of extended transsphenoidal approaches, transcranial approaches of Type 2 and also Type 3 lesions may be more and more replaced.

\section{ENDOSCOPIC PROCEDURES}

Endoscopic procedures are usually considered in occlusive hydrocephalus caused by tumor cysts of the foramen of Monroi. The small size of instruments insertable through the working canals of the endoscope allows only biopsies of the tumor and prevents larger resections. The standard access is a paramedian frontal burr hole in front of the coronal suture. After transcortical puncture of the lateral ventricle, the endoscope can be moved inside the inner CSF space through the foramen of Monroi within some limits. Besides cyst punctures and biopsies (Oppido et al., 2011), catheters can be placed under optic control (Figure 5).

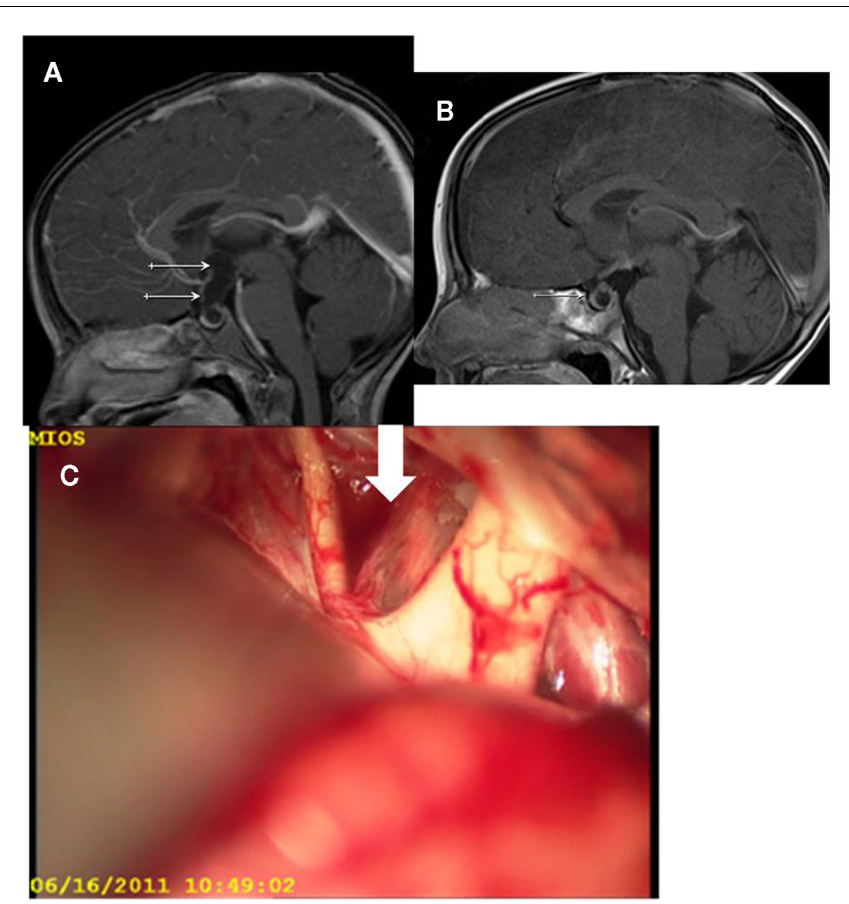

FIGURE 3 | (A,B) Pre- and postoperative MRI of a subtotal resection of a craniopharyngioma extending into the third ventricle up to the mammillary bodies in a 4-year-old child. The postoperative MRI shows remaining intrasellar cystic tumor. Because of missing pneumatization of the sphenoid sinus a transcranial, pterional approach was chosen. The pituitary stalk could be preserved in this case. The patient is under close follow-up, in case of tumor growth prior to pneumatization of the sphenoid sinus, radiotherapy will be considered. (C) The intraoperative photo shows the optic nerves up to the chiasm as well as the spread pituitary stalk (arrow) within the cystic tumor (see parallel running small vessels of the pituitary stalk).

\section{INTRACYSTIC THERAPIES}

Stereotactic placement of catheters into craniopharyngioma cysts with consecutive injection of either radioactive or chemotherapeutic agents has been performed (Steinbok and Hukin, 2010; Barriger et al., 2011). More recently, the use of interferon-alpha as a therapeutic agent was reported (Cavalheiro et al., 2010). These procedures are limited to mostly cystic lesions, which are difficult to reach by others procedures. Prior to injection of the chosen agent it has to be confirmed, that no leakage into the subarachnoid space is possible. Severe complications have been reported (Linnert and Gehl, 2009).

\section{STRATEGIES}

Complete resection of the tumor may be considered the most appealing strategy, if feasible. This strategy includes resection of the outer tumor capsule adjacent to healthy tissue and may sacrifice functional tissue, leading to endocrine dysfunction as well as hypothalamic damage. In cases of preoperative panhypopituitarism, less precautions have to be taken by the surgeon and an aggressive approach seems justified, as long as the hypothalamus is not involved. However, from our own experience as well as from the literature, a true CR is only achieved in a limited number of patients. Also, the criteria of "CR" vary, since some authors 


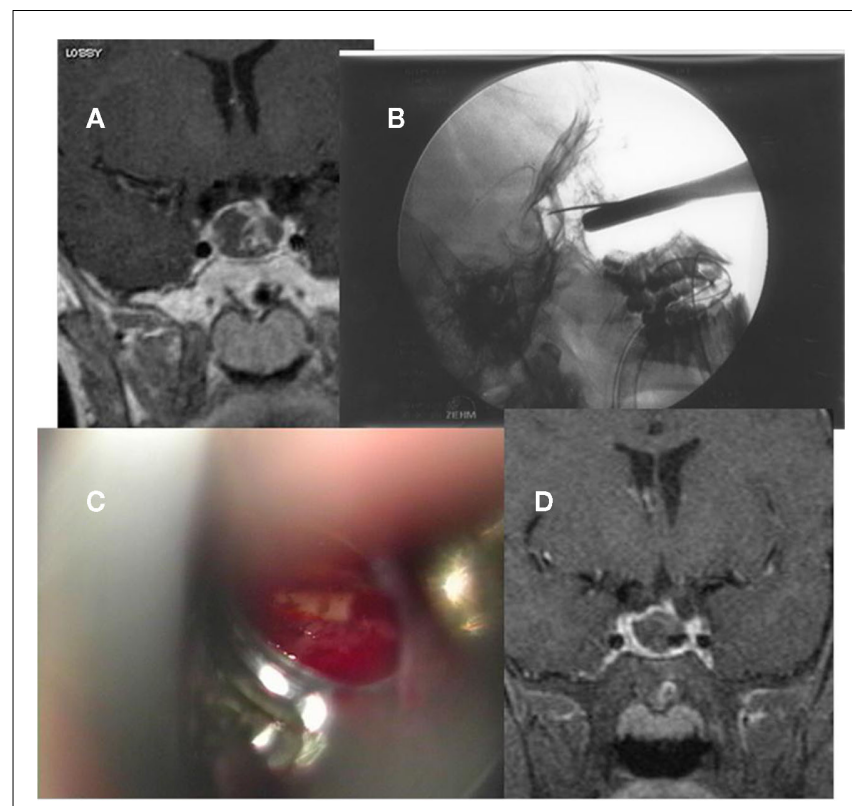

FIGURE 4 | (A) Preoperative contrast enhanced MRI showing an infradiaphragmatic tumor rest after a previous transcranial surgery of a large craniopharyngioma. (B) Intraoperative fluoroscopy showing the surgical approach prior to opening of the sellar floor. Notice the catheter connected to a Rickham reservoir reaching the suprasellar region, which was implanted during the previous procedure. (C) Intraoperative microscopic view showing the catheter tip from the sella using a special mirror technique (Lüdecke technique). (D) Early postoperative MRI showing the extent of tumor resection. Up to today, no recurrence is reported.

consider the intraoperative surgical assessment, other papers a postoperative imaging study, or a combination of both. In general, Type 1 and Type 2 lesions may allow a CR without severe endocrine dysfunction, whereas in Type 3 lesions this strategy is usually combined with a high morbidity.

Gross-total resection (GTR) comprises near CR (>95\%) of the lesion, leaving, e.g., calcified remnants to the pituitary stalk or minimal tumor rests within the hypothalamic tissue. This result is more frequently reported than $\mathrm{CR}$, depending on the location of the craniopharyngioma. Tumor control rates seem acceptable, although combined with a high rate of endocrine morbidity. In general, radiotherapy will only be considered, after a recurrence of disease is visible in imaging studies. However, this topic is currently under investigation. The evaluation of resection extend and therefore the difference between GTR and CR should rely on imaging quality and the surgeon's intraoperative assessment but remains biased to some degree.

Subtotal resection (STR), leaving considerable tumor rests in situ, is a common result of craniopharyngioma surgery. For these patients, radiotherapy is considered after surgery. It is an ongoing discussion, whether radiotherapy should be administered immediately after surgery or only after proven regrowth of the residual disease. Tumor control rates of STR and radiotherapy are reported similar to GTR, however, morbidity rates seem lower.

A Biopsy $(B Y)$ is usually performed in cases of endoscopic cyst punctures for hydrocephalus to confirm the diagnosis or by

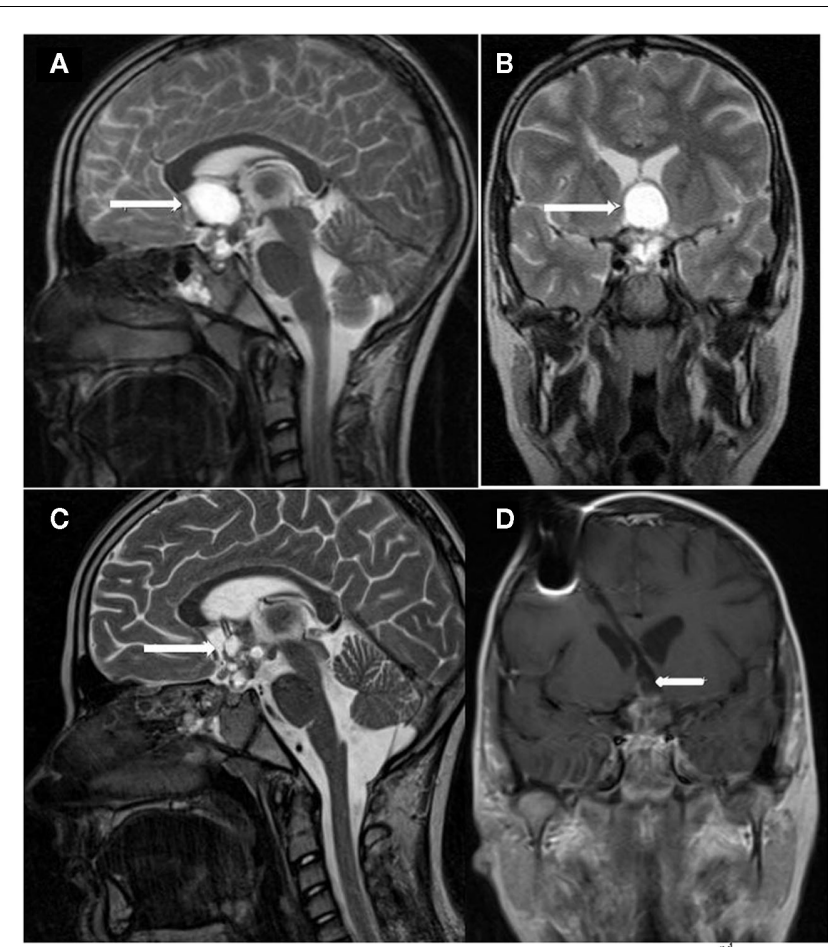

FIGURE $\mathbf{5}$ | (A,B) Preoperative solid and cystic lesion with large cyst within the third ventricle, causing headaches. T2 weighed images. (C,D)

Postoperative MRI after endoscopic drainage of the cyst and insertion of a catheter into the cyst, connected with a frontal Rickham reservoir. Unfortunately, the infrachiasmatic cysts enlarged in size during follow-up prior to radiotherapy, requiring additional surgery (not shown).

stereotactic procedures, e.g., during catheter implantation prior to intracystic therapies.

\section{DISCUSSION}

Craniopharyngiomas are classified as WHO Grade 1 tumors. The 10 year survival rate is found to be over $90 \%$ (Mortini et al., 2011; Müller, 2011), however, morbidity is high and recurrences are common. The surgical expertise as well as the size of the tumor/site of origin seems to be the most reliable factors predicting outcome in patients with craniopharyngiomas (Reschke et al., 2006; Spoudeas et al., 2006; Zada and Cappabianca, 2010; Müller et al., 2011; Qi et al., 2011). Whereas the tumor size is an unchangeable preoperative factor, the surgical strategy can be varied in patients. Early publications already concluded, that no forceful attempt should be made to achieve CR to avoid resulting morbidity (Mori et al., 1980). Perioperative fatal complications are reported in up to 3\% of craniopharyngioma surgery in recent publications (Yamada et al., 2010; Mortini et al., 2011). The "traditional" surgical strategy of choice is to aim for a complete/GTR of the lesion. Some surgeons report complete surgical removal in up to $70 \%$, however, recurrence rates of $25 \%$ are reported by the same group (Mortini et al., 2011), leaving some doubt of the extent of resection. Therefore, the definition of complete surgical removal has to be strict to avoid misleading expectations 
for follow-up. Nowadays, the intraoperative evaluation of resection extend should be confirmed by postoperative MR and CT imaging.

In cases of existing preoperative panhypopituitarism, an aggressive surgical strategy seems justified, since accompanied surgical damage is minimal. Exceptions are hypothalamic involvement; hypothalamic obesity is a feared complication especially in children. Karavitaki et al. (2005) found after a 10-year follow-up phase up to $40 \%$ of patients suffering from obesity. As known from histological specimen resected during surgery, the tumors show finger-like invasion into brain tissue (Burghaus et al., 2010). The surgical attempt to resect these parts will damage the adjacent brain tissue. Müller et al. (2011) found, that the risk of hypothalamic damage increased, when tumors extend beyond the mammillary bodies. Van Gompel et al. (2010) reported that hypothalamic signal changes in T2 weighed MR images as well as irregular contrast enhancement was found to correlate with and predict hypothalamic involvement. In another recent publication, Steno et al. (2011) found a higher morbidity after surgery for intraventricular tumors, when comparing suprasellar extraventricular tumor extension with intraventricular tumor extension.

There has been debate, whether a GTR is more favorable regarding outcome compared with STR. In terms of recurrence, Karavitaki et al. (2005) concluded, that gross-total removal provides favorable results. On the contrary, Schubert et al. (2009) found a more favorable outcome in patients with less invasive procedures compared to more radical approaches. Other authors found comparable rates of recurrence between GTR and STR combined with radiotherapy (Becker et al., 1999; Sughrue et al., 2011). Sughrue et al. performed a statistical analysis including 274 studies regarding craniopharyngioma-treatment in 2011 concluding that GTR results in higher rates of postoperative endocrinopathy and panhypopituitarism which might reach up to threefold compared to STR and radiotherapy (Sughrue et al., 2011). Recurrence rates of up to $36 \%$ after surgical treatment alone were reported by Winkfield et al. (2011) compared to recurrence rates of 5\% when limited surgery was combined with postoperative radiotherapy (seven times higher risk for recurrence). As expected, the morbidity risk increases in these patients with more aggressive approaches. Sughrue et al. (2011) found that patients receiving GTR had over 2.5 times the rate of developing at least one endocrinopathy compared to patients receiving STR or STR plus radiotherapy. Abe and Ludecke (1997) concluded that the concept of subtotal

\section{REFERENCES}

Abe, T., and Ludecke, D. K. (1997). Recent results of primary transnasal surgery for infradiaphragmatic craniopharyngioma. Neurosurg. Focus 3, E4.

Barriger, R. B., Chang, A., Lo, S. S., Timmerman, R. D., DesRosiers, C., Boaz, J. C., and Fakiris, A. J. (2011). Phosphorus-32 therapy for cystic craniopharyngiomas. Radiother. Oncol. 98, 207-212.

Becker, G., Kortmann, R. D., Skalej, M., and Bamberg, M. (1999). The role of radiotherapy in the treatment of

removal with preservation of pituitary functions seemed justified, especially in childhood.

Regarding the surgical access strategy, it is generally accepted that the transsphenoidal approach is the first choice in infradiaphragmatic craniopharyngiomas with sellar enlargement (Abe and Ludecke, 1997; Yamada et al., 2010). Over the last years, several reports of extended approaches to suprasellar craniopharyngiomas have been published (Gardner et al., 2008; Jane et al., 2010; Yamada et al., 2010). These extended transsphenoidal approaches for supradiaphragmatic tumors are connected with a different incidence of endocrinopathies and neurological complications when compared to infradiaphragmatic lesions, especially when complete or GTR is attempted (Jane et al., 2010). CSF fistulas are another complication, which needs meticulous techniques for prevention. It seems necessary to mention, that success as well as complications are connected with the experience of the surgeon. In comparison to transcranial procedures, potential advantages include the avoidance of craniotomy and brain retraction and reduced neurovascular manipulation (Dehdashti et al., 2009). Whether the transsphenoidal approach will more and more replace transcranial techniques, has to be awaited.

\section{CONCLUSION}

The treatment of childhood craniopharyngioma requires an interdisciplinary approach. In many cases, surgical options alone provide immediate relief of compression symptoms. Restitution of preoperative pituitary insufficiencies is not common. CR cannot be achieved in many cases and without widespread consequences for the patients' quality of life. The choice of the "right" surgical approach, especially for Type 2 and Type 3 tumors, can be difficult and controversial and should - from the author's point of view - be in the hands of highly experienced neurosurgi$\mathrm{cal} /$ neuropediatric centers, offering all surgical techniques. Every patient should receive an individually tailored treatment. Recurrences are frequent and require a close and continuous follow-up of the children. Adjuvant radiotherapy should be considered after incomplete surgical resection. The best timing for postoperative radiotherapy remains to be examined.

\section{ACKNOWLEDGMENTS}

The authors thank Dieter K. Lüdecke, MD, and Manfred Westphal, $\mathrm{MD}$, whose surgical expertise led to the current understanding of craniopharyngioma treatment at UKE.

Silva, N. S., Pettorini, B. L., and Toledo, S. R. (2010). Craniopharyngiomas: intratumoral chemotherapy with interferon-alpha: a multicenter preliminary study with 60 cases. Neurosurg. Focus 28, E12.

Coppens, J. R., and Couldwell, W. T. (2010). Staged use of the transsphenoidal approach to resect superior third ventricular craniopharyngiomas. Minim. Invasive Neurosurg. 53, 40-43.

Crowley, R. K., Hamnvik, O. P., O'Sullivan, E. P., Behan, L. A., Smith, D., Agha, A., and Thompson, C.
J. (2010). Morbidity and mortality in patients with craniopharyngioma after surgery. Clin. Endocrinol. (Oxf.) 73, 516-521.

Dehdashti, A. R., Ganna, A., Witterick, I., and Gentili, F. (2009). Expanded endoscopic endonasal approach for anterior cranial base and suprasellar lesions: indications and limitations. Neurosurgery 64, 677-687.

Fahlbusch, R., and Hofmann, B. M. (2008). Surgical management of giant craniopharyngiomas. Acta Neurochir. (Wien) 150, 1213-1226. 
Fernandez-Miranda, J. C., Gardner, P. A., Snyderman, C. H., Devaney, K. O., Strojan, P., Suárez, C., Genden, E. M., Rinaldo, A., and Ferlito, A. (2011). Craniopharyngioma: a pathologic, clinical, and surgical review. Head Neck. doi: 10.1002/hed.21771. [Epub ahead of print].

Flitsch, J., Lüdecke, D. K., Stahnke, N., Wiebel, J., and Saeger, W. (2000). Transsphenoidal surgery for pituitary gigantism and galactorrhea in a 3.5 year old child. Pituitary 2, 261-267.

Gardner, P. A., Kassam, A. B., Snyderman, C. H., Carrau, R. L., Mintz, A. H., Grahovac, S., and Stefko, S. (2008). Outcomes following endoscopic, expanded endonasal resection of suprasellar craniopharyngiomas: a case series. J. Neurosurg. $109,6-16$.

Jane, J. A. Jr., Kiehna, E., Payne, S. C., Early, S. V., and Laws, E. R. Jr. (2010). Early outcomes of endoscopic transsphenoidal surgery for adult craniopharyngiomas. Neurosurg. Focus 28, E9.

Karavitaki, N., Brufani, C., Warner, J. T., Adams, C. B., Richards, P., Ansorge, O., Shine, B., Turner, H. E., and Wass, J. A. (2005). Craniopharyngiomas in children and adults: systematic analysis of 121 cases with long-term follow-up. Clin. Endocrinol. (Oxf.) 62, 397-409.

Kitano, M., and Taneda, M. (2009). Extended transsphenoidal surgery for suprasellar craniopharyngiomas: infrachiasmatic radical resection combined with or without a suprachiasmatic trans-lamina terminalis approach. Surg. Neurol. 71, 290-298.

Komotar, R. J., Roguski, M., and Bruce, J. N. (2009). Surgical management of craniopharyngiomas. J. Neurooncol. 92, 283-296.

Konovalov, A. N. (1993). Microsurgery of tumours of diencephalic region. Neurosurg. Rev. 6, 37-41.

Linnert, M., and Gehl, J. (2009). Bleomycin treatment of brain tumors: an evaluation. Anticancer Drugs 20, 157-164.

Liu, J. K., Christiano, L. D., Gupta, G., and Carmel, P. W. (2010). Surgical nuances for removal of retrochiasmatic craniopharyngiomas via the transbasal subfrontal translamina terminalis approach. Neurosurg. Focus 28, E6.

Lustig, R. H., Post, S. R., Srivannaboon, K., Rose, S. R., Danish, R. K., Burghen, G. A., Xiong, X., Wu, S., and Merchant, T. E. (2003). Risk factors for the development of obesity in children surviving brain tumors. J. Clin. Endocrinol. Metab. 88, 611-616.

Maira, G., Anile, C., Colosimo, C., and Cabezas, D. (2000). Craniopharyngiomas of the third ventricle: translamina terminalis approach. Neurosurgery $47,857-863$.

Mori, K., Handa, H., Murata, T., Takeuchi, J., Miwa, S., and Osaka, K. (1980). Results of treatment for craniopharyngioma. Childs Brain 6, 303-312.

Mortini, P., Losa, M., Pozzobon, G., Barzaghi, R., Riva, M., Acerno, S., Angius, D., Weber, G., Chiumello, G., and Giovanelli, M. (2011). Neurosurgical treatment of craniopharyngioma in adults and children: early and long-term results in a large case series. J. Neurosurg. 114, 1350-1359.

Müller, H. L. (2011). Consequences of craniopharyngioma surgery in children. J. Clin. Endocrinol. Metab. 96, 1981-1991.

Müller, H. L., Gebhardt, U., Teske, C., Faldum, A., Zwiener, I., WarmuthMetz, M., Pietsch, T., Pohl, F., Sörensen, N., Calaminus, G., and The Study Committee of Kraniopharyngeom 2000 (2011). Postoperative hypothalamic lesions and obesity in childhood craniopharyngioma: results of the multinational prospective trial Kraniopharyngeom 2000 after 3-year follow-up. Eur. J. Endocrinol. 165, 17-24.

Ondruch, A., Maryniak, A., Kropiwnicki, T., Roszkowski, M., and Daszkiewicz, P. (2011). Cognitive and social functioning in children and adolescents after the removal of craniopharyngioma. Childs Nerv. Syst. 27, 391-397.

Oppido, P. A., Fiorindi, A., Benvenuti, L., Cattani, F., Cipri, S., Gangemi, M., Godano, U., Longatti, P., Mascari, C., Morace, E., and Tosatto, L. (2011). Neuroendoscopic biopsy of ventricular tumors: a multicentric experience. Neurosurg. Focus 30, E2.

Qi, S., Pan, J., Lu, Y., Gao, F., Cao, Y., Peng, J., and Zhang, X. (2011). The impact of the site of origin and rate of tumour growth on clinical outcome in children with craniopharyngiomas. Clin. Endocrinol. (Oxf.). [Epub ahead of print].

Rennert, J., and Doerfler, A. (2007). Imaging of sellar and parasellar lesions. Clin. Neurol. Neurosurg. 109 , 111-124.

Reschke, K., Busse, S., Mohnike, K., Buchfelder, M., Ranke, M., Fahlbusch, R., and Lehnert, $\mathrm{H}$. (2006). CranioNet - an interdisciplinary strategy for craniopharyngioma. Dtsch. Med. Wochenschr. 131 , 821-824.

Schubert, T., Trippel, M., Tacke, U., van Velthoven, V., Gumpp, V., Bartelt S., Ostertag, C., and Nikkhah, G. (2009). Neurosurgical treatment strategies in childhood craniopharyngiomas: is less more? Childs Nerv. Syst. 25, 1419-1427.

Smee, R. I., Williams, J. R., Kwok, B. Teo, C., and Stening, W. (2011). Modern radiotherapy approaches in the management of craniopharyngiomas. J. Clin. Neurosci. 18 613-617.

Spoudeas, H. A., Saran, F., and Pizer, B. (2006). A multimodality approach to the treatment of craniopharyngiomas avoiding hypothalamic morbidity: a UK perspective. J. Pediatr. Endocrinol. Metab. 19(Suppl. 1), 447-451.

Steinbok, P., and Hukin, J. (2010). Intracystic treatments for craniopharyngioma. Neurosurg. Focus 28, E13.

Steno, J., Bizik, I., Steno, A., and Matejcik, V. (2011). Craniopharyngiomas in children: how radical should the surgeon be? Childs Nerv. Syst. 27, 41-54.

Sughrue, M. E., Yang, I., Kane, A. J., Fang, S., Clark, A. J., Aranda, D., Barani, I. J., and Parsa, A. T. (2011). Endocrinologic, neurologic, and visual morbidity after treatment for craniopharyngioma. J. Neurooncol. 101, 463-476.

Van Gompel, J. J., Nippoldt, T. B., Higgins, D. M., and Meyer, F. B. (2010). Magnetic resonance imaging-graded hypothalamic compression in surgically treated adult craniopharyngiomas determining postoperative obesity. Neurosurg. Focus 28, E3.

Winkfield, K. M., Tsai, H. K., Yao, X., Larson, E., Neuberg, D., Pomeroy, S. L., Ullrich, N. J., Cohen, L. E., Kieran, M. W., Scott, R. M., Goumnerova, L. C., and Marcus, K. J. (2011). Long-term clinical outcomes following treatment of childhood craniopharyngioma. Pediatr. Blood Cancer 56, 1120-1126.

Yamada, S., Fukuhara, N., Oyama, K., Takeshita, A., Takeuchi, Y., Ito, J. and Inoshita, N. (2010). Surgical outcome in 90 patients with craniopharyngioma: an evaluation of transsphenoidal surgery. World $\mathrm{Neu}$ rosurg. 74, 320-330.

Yan, H. J. (2007). Epidural hematoma following use of a three-point skull clamp. J. Clin. Neurosci. 14, 691-693.

Zada, G., and Cappabianca, P. (2010). Transsphenoidal surgery for craniopharyngiomas: the lessons of experience, timing, and restraint. World Neurosurg. 74 256-258.

Conflict of Interest Statement: The authors declare that the research was conducted in the absence of any commercial or financial relationships that could be construed as a potential conflict of interest.

Received: 08 August 2011; paper pending published: 12 September 2011; accepted: 21 November 2011; published online: 23 December 2011.

Citation: Flitsch J, Müller HL and Burkhardt $T$ (2011) Surgical strategies in childhood craniopharyngioma. Front. Endocrin. 2:96. doi: 10.3389/fendo.2011.00096

This article was submitted to Frontiers in Pituitary Endocrinology, a specialty of Frontiers in Endocrinology.

Copyright (C) 2011 Flitsch, Müller and Burkhardt. This is an open-access article distributed under the terms of the Creative Commons Attribution Non Commercial License, which permits noncommercial use, distribution, and reproduction in other forums, provided the original authors and source are credited. 